\title{
Study of Influence of Precursor Decomposition on Oxide and Wet Chemical Methods in Synthesis of $\mathrm{Ni}-\mathrm{Zn}$ Ferrites
}

\author{
Vikas J. Pissurlekar \\ Department of Chemistry, P.E.S."s S.R.S.N College of Arts and Science, Ponda, Goa. - 403 401, India
}

\begin{abstract}
Nickel zinc ferrite of composition $\mathrm{Ni}_{0.6} \mathrm{Zn}_{0.4} \mathrm{Fe}_{2} \mathrm{O}_{4}$ was prepared by two different routes using solid oxides of nickel, zinc and iron in the first and their nitrates in solution in second method. These two mixtures were treated with the same ligand to produce the precursors. These two precursors were then decomposed to obtain nano size ferrites. The study was carried out to see the influence of the precursor decomposition on structural, electrical and magnetic properties on both these routes of synthesis on Ni-Zn ferrite samples. The powders were characterized by infrared spectroscopy (IR), X-ray diffraction (XRD), scanning electron microscopy (SEM) and magnetic measurement of hysteresis curves. The X-ray diffraction patterns indicated that the samples in both decomposition produced single phase spinel structure crystalline nano ferrite powders. The lattice parameter for oxide method was found to be lower with smaller crystallite size in comparison to wet chemical method. The average crystallite size was 17 and 46 nm and saturation magnetization was 33.17 and 58.24 emu/g, respectively, for the samples obtained from oxides and nitrates. The samples synthesized with nitrates in wet chemical method showed better magnetic properties.
\end{abstract}

Keywords: Two routes; Precursor; Lattice parameter; Crystallite size; Magnetic property

\section{Introduction}

There is a growing interest in magnetic spinel soft ferrite nano materials. Amongst them nickel zinc ferrite nanoparticles are getting increasing attention due to their versatility in structural, electrical and magnetic properties. They are having applications in multiple fields as a part of the sensors, as a catalyst, permanent magnets, recording heads, antenna rods, telecommunication devices, loading coils, etc [1,2]. There is growing research for using nickel zinc ferrite nanoparticles due to their excellent magnetic properties, high chemical stability and monodispersity for biomedical applications, as they also have a better biological compatibility or antimicrobial activity, in areas such as treatment of hyperthermia, targeted drug delivery and magnetic resonance imaging $[3,4]$.

The cation distribution over the tetrahedral and octahedral sites in the spinel structure is strongly dependent on the ionic radii and concentration of the substituted divalent metal ions. Also mode of preparations like ceramic [5] coprecipitation [6, 7], hydrothermal [8], sol-gel [9, 10], reverse micelle [11] plays an important role in development of particle size and properties of the material. The ferrite synthesis by wet methods has lots of advantages over the solid state methods as they are convenient, economical due to low costs, environmental friendly precursors, high purity of the products obtained and a better control of structural features, therefore desirable properties [12,13 ]. In recent times combustion synthesis is emerging as a very popular method for synthesis and processing of advanced ferrite composites and ferromagnetic nanomaterials. This is due to higher purity of materials prepared by the combustion process, which is due to expulsion of impurities as volatile species at high temperatures during the reactions [14]. It is reported in the literature $[15,16]$ that the many nanopowdered systems have degradation in their magnetic properties while maintaining the higher electrical resistivity in the range of $10^{5}-10^{11} \mathrm{Ohm}-\mathrm{cm}$ [17]. In general, the bulk ferrite materials are found to show saturation magnetization, in the range of $40-110 \mathrm{emu} / \mathrm{g}$ [18], whereas for nano ferrites it varies from 10 to $70 \mathrm{emu} / \mathrm{g}$ [19]. There is always a need for a systematic investigation to improve the electrical resistivity and saturation magnetization of nano ferrite materials as these properties depend on the processing conditions.

In this paper, ceramic procedure has been modified with help of a chemical method to obtain ferrite material. This method involving partly mechano- and chemical method makes use of ball-mill for mixing of oxides and oxalate ligand for obtaining initial compound, before decomposition.

In wet chemical method, a precursor is first prepared using the same oxalate ligand as in the first method in aqueous solution from which it is isolated in solid form and then decomposed to obtain nickel zinc ferrite nanoparticles by the auto-combustion method. The purpose of present study is to investigate the effect of precursor decomposition on the morphological, structural, magnetic and electrical properties on the ferrite nanoparticles obtained from the two methods.

\section{Experimental Details}

In the present study nickel zinc ferrite with different starting materials was synthesized using following two routes:

a) Synthesis of $\mathrm{Ni}_{0.6} \mathrm{Zn}_{0.4} \mathrm{Fe}_{2} \mathrm{O}_{4}$ ferrites by oxide method: In a typical experiment, for the preparation of $\mathrm{Ni}_{0.6} \mathrm{Zn}_{0.4} \mathrm{Fe}_{2} \mathrm{O}_{4}$, a mixture of $\mathrm{NiO}, \mathrm{ZnO}$ and $\mathrm{Fe}_{2} \mathrm{O}_{3}$ in stoichiometric amount was ball milled for 10 hours at 80 rpm speed. It was then treated with aqueous oxalate hydrazinate ligand to a thick paste. Further the paste was dried on a burner using silica crucible. On drying it got ignited and decomposed into powder. This powder was used for characterization and study of structural, electrical and magnetic properties. 


\section{International Journal of Science and Research (IJSR) \\ ISSN (Online): 2319-7064}

Index Copernicus Value (2013): 6.14 | Impact Factor (2014): 5.611

b) Synthesis of $\mathrm{Ni}_{0.6} \mathrm{Zn}_{0.4} \mathrm{Fe}_{2} \mathrm{O}_{4}$ ferrites by wet chemical method:

In a typical experiment, calculated amount of $\mathrm{Ni}\left(\mathrm{NO}_{3}\right)_{2} \cdot 6 \mathrm{H}_{2} \mathrm{O}, \mathrm{Zn}\left(\mathrm{NO}_{3}\right)_{2} \cdot 6 \mathrm{H}_{2} \mathrm{O}$ and $\mathrm{Fe}\left(\mathrm{NO}_{3}\right)_{3} \cdot 9 \mathrm{H}_{2} \mathrm{O}$ were dissolved in minimum quantity of distilled water. It was then treated with aqueous oxalate hydrazinate ligand. The mixture was then kept for drying on a hot plate in a silica crucible, on drying undergoes auto combustion- self decomposition- to give the product. This powder was used for characterization and study of structural, electrical and magnetic properties.

The structural characterization of the prepared Ni-Zn ferrite nanoparticles was carried out using Rigaku, X-ray advance Power diffractometer using $\mathrm{Cu} \mathrm{K} \alpha$ radiation $(\lambda=1 \cdot 54183$ $\AA)$. The step size employed was $0 \cdot 02^{\circ}$, in the range of $20^{\circ}-$ $80^{\circ}$. The IR spectra of Ni-Zn ferrite samples were recorded by using FTIR Shimadzu Model IR prestige 21 series spectrophotometer. The average particle size $\mathrm{T}$ was calculated using most intense peak (311) employing the Scherer formula. The particle size and morphology studies were carried out using Scanning Electron Microscope Model JEOL 5800LV. The saturation magnetization measurements of all the samples were carried out at room temperature using Pulse Field Magnetic Hysteresis Loop Tracer, supplied by Magneta India Model PFMHT-1.

\section{Results and Discussion}

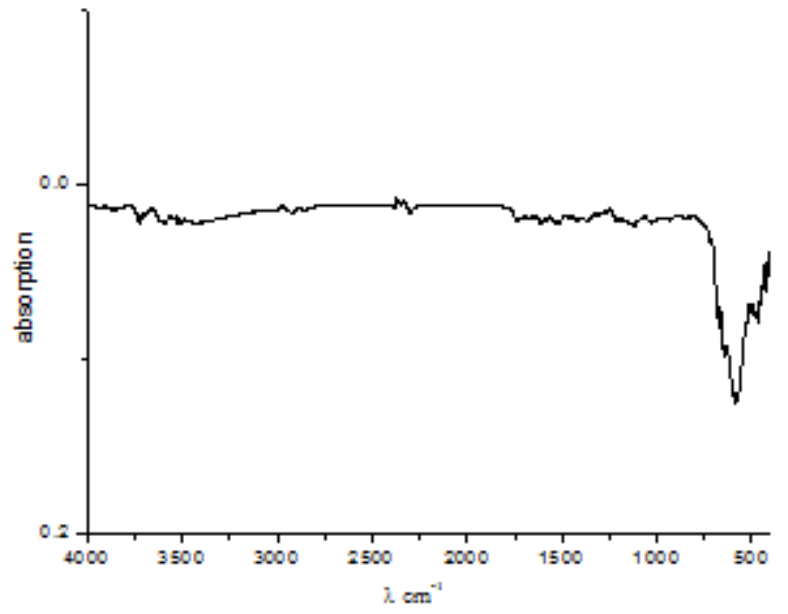

(a)

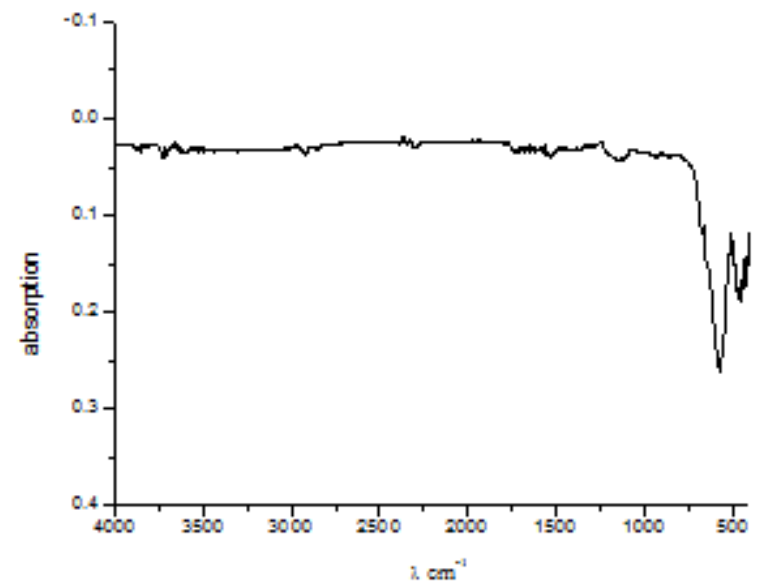

(b)

Figure 1: IR Spectra of $\mathrm{Ni}_{0.6} \mathrm{Zn}_{0.4} \mathrm{Fe}_{2} \mathrm{O}_{4}$ obtained by (a) oxide method and (b) wet chemical method
The infrared spectrum of $\mathrm{Ni}_{0.6} \mathrm{Zn}_{0.4} \mathrm{Fe}_{2} \mathrm{O}_{4}$ ferrite sample prepared by solid oxides and by wet chemical method recorded in the range of $4000-400 \mathrm{~cm}^{-1}$ are shown in Fig. 1 (a) and (b) respectively, The IR spectrum of sample show two peaks, one in the range $600-550 \mathrm{~cm}^{-1}$ and the other 450 $385 \mathrm{~cm}^{-1}$ corresponding to:

(a) $\mathrm{Me}_{\mathrm{T}}-\mathrm{O}-\mathrm{MeO}$ stretching vibration $600-550 \mathrm{~cm}^{-1}$

(b) $\mathrm{MeO} \longleftrightarrow 0$ stretching vibration $450-385 \mathrm{~cm}^{-1}$

Here $\mathrm{O}$ is oxygen, $\mathrm{Me}_{\mathrm{O}}$ is metal in the octahedral site and $\mathrm{Me}_{\mathrm{T}}$ in the tetrahedral site. The metal oxygen absorption bands (a) and (b) are pronounced for all spinel structures and essentially for ferrites, which are also seen in the sample. For $\mathrm{Ni}_{0.6} \mathrm{Zn}_{0.4} \mathrm{Fe}_{2} \mathrm{O}_{4}$ sample synthesized by oxide method two bands are at $592 \mathrm{~cm}^{-1}$ and $473 \mathrm{~cm}^{-1}$ and for the sample synthesized by wet chemical method two bands are at 565 $\mathrm{cm}^{-1}$ and $470 \mathrm{~cm}^{-1}$. IR spectral data of the ferrite samples are in agreement with the reported value $[20,21]$.

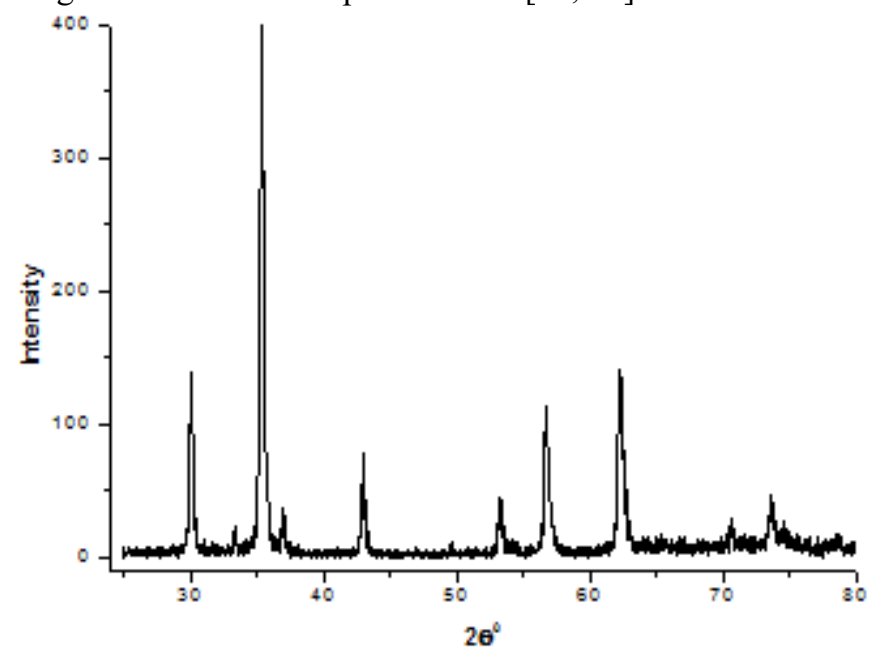

(a)

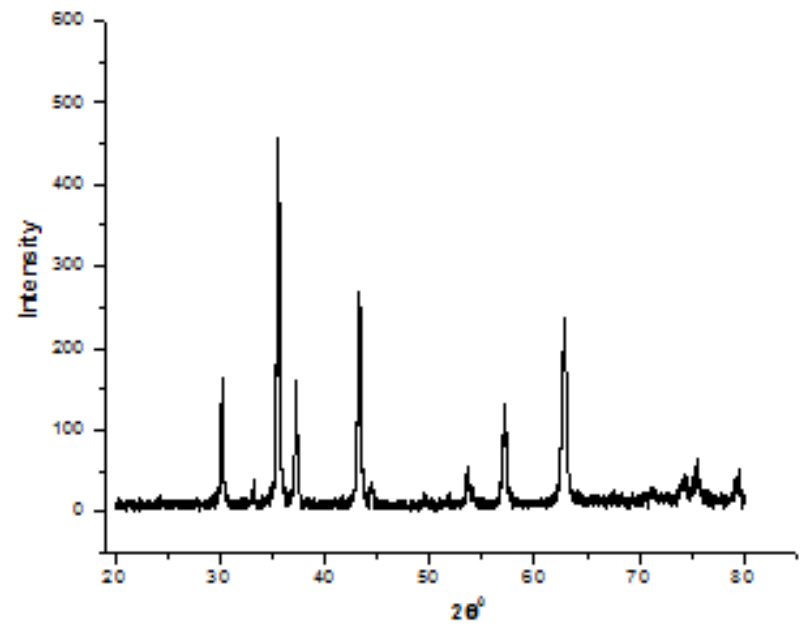

(b)

Figure 2: XRD patterns of the samples obtained by (a) oxide method and (b) wet chemical method.

Fig. 2 (a) and (b) shows the X-ray diffraction patterns of samples $\mathrm{Ni}_{0.6} \mathrm{Zn}_{0.4} \mathrm{Fe}_{2} \mathrm{O}_{4}$ nanoparticles prepared by the two methods. All the peaks correspond to cubic spinel ferrite structure for both the samples and confirm the formation of single phase ferrite. 


\section{International Journal of Science and Research (IJSR) \\ ISSN (Online): 2319-7064}

Index Copernicus Value (2013): 6.14 | Impact Factor (2014): 5.611

The values for lattice constants were calculated for $\mathrm{Ni}_{0.6} \mathrm{Zn}_{0.4} \mathrm{Fe}_{2} \mathrm{O}_{4}$ nanoparticles using the characteristic (311) peak from XRD pattern for both methods. The values of lattice constants are $8.3426 \mathrm{~A}^{0}$ for oxide method and 8.3867 $\mathrm{A}^{0}$ for chemical method. The lattice constant,$a$ ' is found to be lower for samples prepared by oxide material as compared to wet chemical method which may be attributed to the downsizing of oxide particles during the ball milling which may be responsible for the smaller crystal formation, where as in the case of wet chemical method it will depend on the energy available during the combustion reaction for the growth of the crystallite.

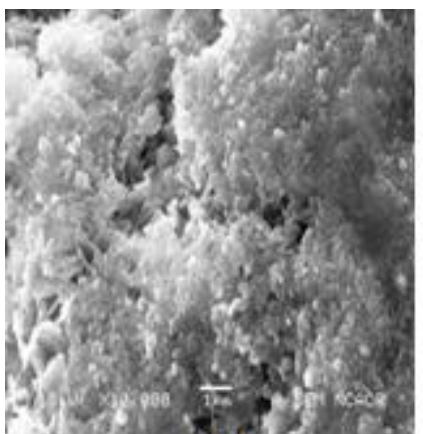

(a)

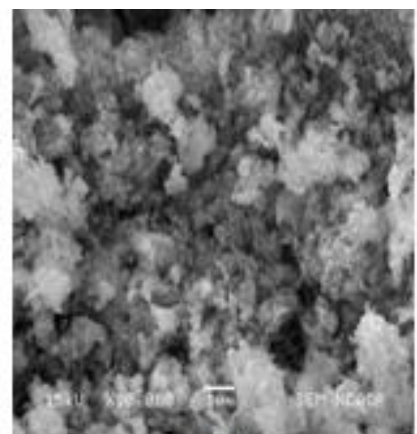

(b)
Figure 3: $\mathrm{SEM}$ images of $\mathrm{Ni}_{0.6} \mathrm{Zn}_{0.4} \mathrm{Fe}_{2} \mathrm{O}_{4}$ obtained by(a) oxide method and (b) wet chemical method.

Average crystallite sizes were calculated by using XRD data by measuring the full-width at half maximum (FWHM) for most intense characteristic (311) peak for both the samples with the help of the Scherer formula. The crystallite sizes are 17 and $46 \mathrm{~nm}$. It is found that crystallite size of the ferrite sample prepared by oxide method is lower than that for wet chemical method it may be due to the lower values of lattice constant due to the ball milling effect on the material size. This is also confirmed by the SEM images shown in figure 3(a ) and (b)where it can be seen that particles are smaller and loosely held in the case of ferrites prepared by oxide method ( fig. 3 (a) ) on other hand wet chemical method gives bigger particles with higher porosity and are agglomerated (fig.3(b)) due to higher magnetic interaction.

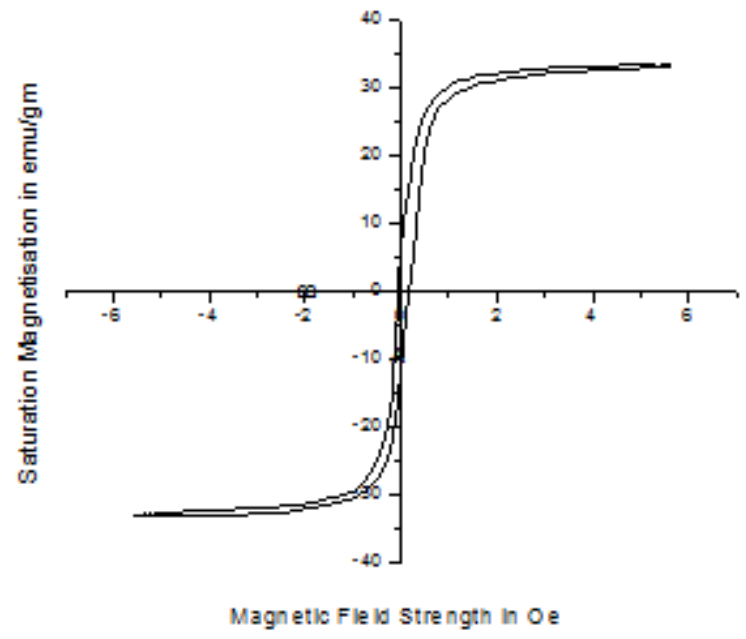

(a)

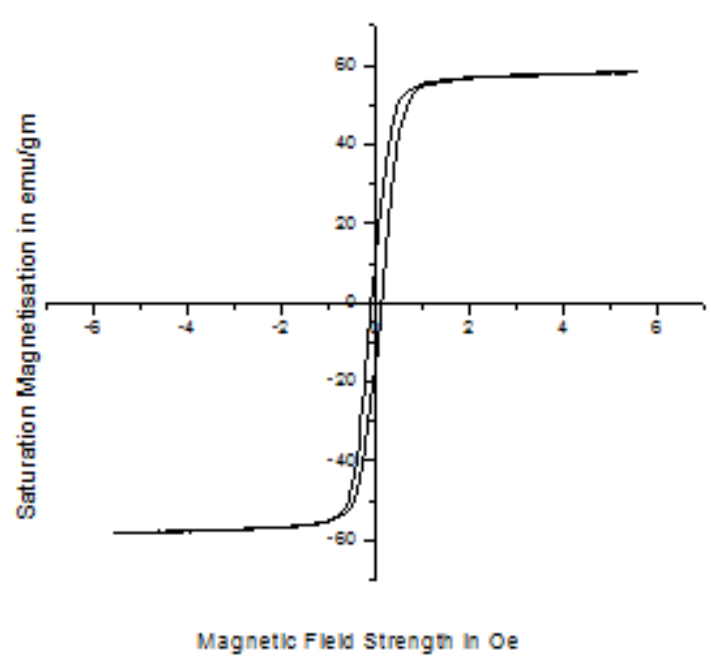

(b)

Figure 4: Saturation Magnetization of $\mathrm{Ni}_{0.6} \mathrm{Zn}_{0.4} \mathrm{Fe}_{2} \mathrm{O}_{4}$ obtained by (a) oxide method and (b) wet chemical method.

Magnetization measurements were carried out at room temperature with a maximum applied magnetic field of 5 kOe An analysis of the two curves indicates that the ferrite powder synthesized with oxides is found to have a lower value of saturation magnetisation of $33.17 \mathrm{emu} / \mathrm{g}$ whereas for the sample synthesized with wet chemical method it is found to be $58.24 \mathrm{emu} / \mathrm{g}$. The main reason for this difference may be attributed to the particle size of the ferrites, synthesized with oxides with lower particle size and nitrates having larger particles, similar observation are made by Costa et al in preparation of $\mathrm{Mn}-\mathrm{Zn}$ ferrite by using urea and glycine as the fuels [22]. It is well known that nano sized particles have small domain areas whose boundaries or domain walls prevent their rotation and/or spin, contributing to reduce their magnetization. Thus, in this work, the powder particles synthesized with wet chemical method were almost $40 \%$ larger than those synthesized with oxides, which may be contributing directly to increase in magnetization due to their larger domain area.. Therefore, the larger particle size of the $\mathrm{Ni}-\mathrm{Zn}$ ferrite powders synthesized by wet chemical method shows the higher saturation magnetization values of $58.24 \mathrm{emu} / \mathrm{g}$.

\section{Conclusions}

Precursor decomposition synthesis using aqueous oxalate hydrazinate ligand with ball milled oxide materials and wet chemical nitrates solution gives the formation of crystalline $\mathrm{Ni}_{0.6} \mathrm{Zn}_{0.4} \mathrm{Fe}_{2} \mathrm{O}_{4}$ nanoparticles. The average crystallite size of the ferrites synthesized with oxides and a wet chemical method was 17 and $46 \mathrm{~nm}$, respectively. Samples synthesized with oxides show the formation of smaller loosely held particles with irregular morphology having lower saturation magnetization. The samples synthesized with wet chemical method presented superior magnetic characteristics with higher saturation magnetization.

\section{Acknowledgements}

The author is grateful to the University Grants Commission (UGC) New Delhi India for the financial support provided by way of minor research project. 


\section{References}

[1] H. Kavas, N. Kasapoglu, A. Baykal, Y. Koseoglu, "Characterization of $\mathrm{NiFe}_{2} \mathrm{O}_{4}$ nanoparticles synthesized by various methods", Chem. Pap. 63(4) (2009) 450455.

[2] E. Rezlescu, L. Sachelarie, P. D. Popa, N. Reslescu, IEEE Trans. Mag. 36 (6) (2000) 3962.

[3] Q.S. Tang, D.S. Zhang, X.M. Cong, M. 1. Wan, L.Q. Jin, Biomaterials 29 (2008) 2673-2679

[4] B.K. Sunkara, R.D.K. Misra, Acta Biomater 4 (2008) 273.

[5] S.S. Kumbhar, M. A. Mahadik, V. S. Mohite, K. Y. Rajpure, J. H. Kim, A. V. Moholkar, C. H. Bhosale, J Magn. Magn. Mater.363 (2014) 114-120

[6] J. Yang, W. Tsuo, F. Yen, "Preparation of ultrafine nickel ferrite powders using mixed $\mathrm{Ni}$ and $\mathrm{Fe}$ tartarates", J. Solid State Chem.145(1999)50-57.

[7] M. A. Gabal, Y.M. Al Angari, Mater. Chem. Phys. 11 (2009) 578 .

[8] U. Wongpratat, S. Meansiri , E. Swatsitang, Microelectronic Engineering 126 (2014) 19-26

[9] A. Ghasemin, M. Mousavinia Ceramics International 40(2014) 2825-2834

[10] V.D. Kapse, S. A. Ghosh, F.C. Raghuwanshi, S. D. Kapse, U.S. Khandekar, Talanta 78 (2009) 19.

[11] A. Kale, S. Gubbala, R. D. K. Misra, J. Magn. Magn. Mater. 277 (2004) 350

[12] M.M. Rashad, E.M. Elsayed, M.M. Moharam, R.M. Abou-Shahba, A.E. Saba, J. Alloys Compd. 486 (2009) 759.

[13]T. J. Shinde, A. B. Gadkari, P. N. Vasambekar, Mater. Chem. Phys. 111 (2008) 87.

[14]R. Parthasarathi, L. Berchmans, R. Preetha, G. Senguttuvan, G. Umapathu, "Combustion synthesis of nanocrystalline nickel ferrite using hexamine as a fuel", Int.J.Self-Propag.High-Temp.Synth. 20 (2011) 236240.

[15] A. Verma, T. C. Goel, R. G. Mendiratta, Mater. Sci. Technol. 16 (2000) 712

[16] S. K. Date, P.A. Joy, P.S. Anil Kumar, B. Sahoo, W. Keune, Phys. Stat. Sol. (c) 1 (12) (2004) 3495

[17] A. Verma, O. P. Thakur, C. Prakash, T.C. Goel, R.G. Mendiratta, Mater. Sci. Eng. B 116 (2005) 1.

[18] S.L. Pereira, H.D. Pfannes, A.A.M. Filho, L.C.B. de Miranda Pinto, M.A. Chıncaro, Mater. Res. 2 (3) (1999) 231

[19] A.S. Albuquerque, J.D. Ardisson, W.A.A. Macedo, M.C.M. Alves, J. Appl. Phys. 87 (9) (2000) 4352.

[20] R.D. Waldron, Phys. Rev. 99 (1955) 1727.

[21] S. Kumar, P Kumar, V Singh, U K Mandal, R Kotnala J Magn Magn. Mater. 379(2015)50-57

[22] A.C.F.M. Costa, V.J. Silva, C.C. Xin, D.A. Vieira, D.R. Cornejo, R.H.G.A. Kiminami, J . Alloys and Compounds 495 (2010) 503-505 